\title{
ROAD LESS TRAVELED: MOTIVATIONS AND PATHWAYS OF FILIPINO LESBIANS AND GAYS IDENTIFYING AS EX-GAYS
}

\author{
Nel Jayson Santos, Aaron Vichard Ang, Sigrid Joyce Dela Paz, \& Daniel Jan Duque \\ Department of Psychology, De La Salle University-Manila (Philippines)
}

\begin{abstract}
This study explores the motivations and the pathways of past self- identifying Filipino lesbians and gays. In this study, the researchers seek to (1) understand the motivations that influenced ex-gays in modifying their sexual orientation and (2) delve more into the different pathways (stages and/or steps) that are involved in the sexual orientation modification of ex-gays specifically in the Philippine context. A semi-structured interview was conducted with 10 self- identified Filipino ex-gays. Inductive thematic analysis was then used to analyze the data and to identify common themes. Four themes emerged as motivations of ex- gays respectively; Identity Dissonance, Spiritual Conviction, Cognitive Reconstruction, and Influential Role Models. Likewise, three themes materialized as common pathways taken by ex- gays, namely; Church Involvement, Accountability/Support Groups, and Adaptation of New Lifestyle. Moreover, the study clarifies the existing definition of being an ex-gay.
\end{abstract}

Keywords: Ex-gay, sexual orientation, and sexual orientation modification process.

\section{Introduction}

\subsection{Motivations of ex-gays}

Ex-gay refers to individuals that experienced some modification in their sexual orientation ranging from exclusive homosexuality to exclusive heterosexuality, or ones either curious, attempting, or claiming to have altered their sexual orientation (Weiss et al., 2010). Prior studies, identify religion as one prevalent motivation for sexual reorientation (Haldeman, 1994). It can be noted that in some cases the individual's spiritual identity proves to be more salient compared to their sexual identity leading them to prioritize faith over sexual orientation (Bartoli \& Gillemi, 2008). Although not all ex-gays in the previous studies reported change, most either (1) no longer interpreted their same-sex attractions requiring them to identify as gays/lesbians or (2) found themselves not entirely homosexual and/or predominantly straight. In addition, factors like strained family relationships, understanding the nature of one's sexual attractions, adoption of new of perspectives, and receiving supportive atmosphere with other ex-gays are also reported as motivations for sexual reorientation (Robinson \& Spivey, 2007).

\subsection{Pathways of ex-gays}

In accordance with Throckmorton (2002), sexual orientation modification process of ex-gays is generally associated with different religious organizations. One of the major Ex-gay Christian ministry in the United States and Canada is the Exodus International, that intends to help lesbian and gay (LG) individuals to lessen their same- sex attraction and eventually promote abstinence over homosexual desires (Burack, 2015). The community utilizes techniques that include strengthening the individual's level of religiosity, and heterosexual identity (Shidlo \& Schroeder, 2002). Likewise, Rosenbuth (2000), describes JONAH, a Jewish ex-gay ministry in Brooklyn, that utilizes Jewish principles aligned with the Torah to help LG individuals in dealing with their homosexual issues. Furthermore, Evergreen International, a Church of Jesus Christ of Latter Day Saints ministry in Utah, also utilizes the religion's teachings and doctrines to aid in same-sex attraction and homosexual behaviors (Robinson, 1998). In the Philippines, religious organizations that promote the ex-gay movement among Filipino Lesbian and Gays are also present (UNDP \& USAID, 2014). One of such organization is the Courage Philippines, an Apostolate of the Catholic that gives spiritual guidance and support to Filipino Lesbians and Gays experiencing same-sex attraction (Campbell, 2010). It centers on helping members to fully surrender themselves to God and cultivate a life of interior chastity (Courage Philippines, 2012). According to Robinson and Spivey (2007), most participants in the west disclosed developing negative and traumatic experiences after going through activities such as engaging in masculine-oriented hobbies, and putting blame on parenting shortcomings for their homosexuality. 


\subsection{Present study}

The literature conveys that the identified motivations and pathways of ex-gays are largely studied in the western context (Weiss et al., 2010). Although ex-gay ministries and their overall goals towards sexual reorientation were presented, specific processes and activities done is yet to be explored. Moreover, motivations of the ex-gay individuals are still to be expanded upon and affirmed with respect to a different cultural context. In the present study, motivation is defined as the factors behind an individual's decision to change. While pathways refer to the overall modification process including practice, activities, techniques, and/or steps taken. The term ex-gay will be limited to lesbian and gay individuals that are previously attracted to the members of the same sex and/or currently claim to have an attraction to the opposite sex or deny any attraction at all. In general, the study aims to answer the following questions:

1. What are the motivations that influenced Filipino ex-gays to modify their sexual orientation?

2. What are the pathways (practices, activities, and/ or steps) involved in the sexual orientation modification of Filipino ex-gays?

\section{Method}

A semi-structured interview was used to aid in determining the participant's motivation in associating themselves as ex-gays and the pathways (stages and or steps) of they came to a point of identifying themselves as former gays. Ten self-identified Filipino ex-gays (four former lesbians and six former gays) participated in the study. Each participant received a consent form via email containing the nature of the study which the researcher ensured was understood and duly signed. Participants were then audio recorded and interviewed for around 45 minutes to an hour, using English and Filipino. Afterwards, the data was transcribed and analyzed for patterns and themes using the Inductive Thematic Analysis approach related to the motivations and pathways of identifying as ex-gays. Throughout the paper pseudonyms were used to identify the participants.

\section{Results}

\subsection{Motivations of Filipino lesbian and gays in modifying their sexual orientation}

Identity Dissonance. Most of the participants manifested having identity dissonance as their initial motivation in modifying their sexual orientation (9 out of 10 participants). Identity Dissonance was described by the participants as having an internal disconnect which included re-emerging feelings of discomfort such as having doubts and guilt at certain points in their homosexual lifestyle. A participant from an ex-gay ministry mentioned about being unhappy when he was still living his homosexual lifestyle and having hesitations toward his personal character.

Spiritual Conviction. Spiritual conviction as a product of faith appear to be a central motivation of Filipino Lesbian and Gays in modifying their sexual orientation (10 out of 10 participants). Although, brought up religiously, not all reported to be religious prior to modifying their sexual orientation. Some are already disconnected with their religiosity in order to realize their lesbian/gay identity but reported being reignited into faith through spiritual encounters or callings that transpired at a particular point of their lives whether through a church service, church activity, and/or answered prayers. These factors led them to compel for change. A participant from a Christian ministry described that he was motivated by his faith and personal encounters with Jesus Christ through bible readings.

Cognitive Reconstruction. Cognitive Reconstruction involves forming new perspectives with regards to their sexual orientation and manifesting a deeper understanding of one's identity (9 out of 10 participants). It also includes the realization of the participants regarding the repetitive and tiring cycle of same-sex relationships and increased awareness of the health related diseases brought about by homosexual relationships. A respondent described that same-sex relationships does not usually last, and may often increase the risk of sexually transmitted diseases

Influential role models. Almost all of the participants mentioned about witnessing a role model that motivated and inspired them to modify their sexual orientation ( 9 out of 10 participants). The role model may also include a person having experienced the same struggle or situation as the participant. In which, these role models have succeeded and persevered in their own attempts to turn away from their homosexual lifestyle. A participant mentioned that how inspiring it is to see people successful in their own pursuits in modifying their lifestyles.

\subsection{Pathways involved in the sexual orientation modification of Filipino lesbians and gays}

Church Involvement. Church involvement appeared to be the common pathway involved in their sexual orientation modification (7 out of 10 participants). Church involvements referred to activities and practices that enriched their faiths. This includes attending church services and activities of the 
church such as bible studies \& retreats, fellowships, and outreach programs. Two participants stated that the different church activities that they had aided them in modifying their sexual orientation.

Accountability/Support Group. All participants reported accountable and supportive environments. Holding sharing meetings helped them to know about themselves. Also, having healthy platonic relationships with their support groups were the primary reasons why most of the participants came back and continued in their sexual modification efforts. A participant mentioned that having supportive environment with fellow community members helped them to know more about themselves.

Adaptation of New Lifestyle. All participants reported avoiding situations and practices that would have make them vulnerable to the gay lifestyle in their sexual reorientation process (10 out of 10 participants). This included ceasing use of dating apps, and limiting interactions with their gay peers. On the other hand, each participant also reported starting certain activities and practices that helped divert their attention from their homosexual lifestyle. This includes frequent church activities and having more personal time of reflection through Bible reading and praying. A participant reported spending more of his time with his family and avoiding places that would make him vulnerable to the homosexual lifestyle.

\section{Discussion}

The findings in the study affirmed faith, as the central driving force in an ex-gay's sexual orientation modification process. Although participants identified parenting and dysfunctional family dynamics as one contributing factor to their gay/lesbian identity, expression of any negativity towards their parents were not seen. Instead, most participants reported better family relationships as they chose to identify as ex-gays. Furthermore, participants in the study reported experiencing no physically or emotionally demanding activities. This may suggest that the approach of Philippine ex-gay communities is less aggressive than that of the ministries in the west, where negative and traumatic experiences from therapy were noted. Lastly, when asked about their current sexual orientation, participants admitted still having same sex attractions, although less powerful and intimate as before. Most of them were not familiar, and as well as hesitant towards the term "ex-gay". However, they preferred to be described as individuals who have turned away from the gay lifestyle striving to live as how God wanted them to be.

\section{References}

Bartoli, E., and Gillemi, A. R. (2008). Continuing to Depolarize the Debate on Sexual Orientation and Religion: Identity and the Therapeutic Process. Professional Psychology: Research and Practice, 39(2), 202-209.

Burack, C. (2015). From Heterosexuality to Holiness: Psychoanalysis and Ex-gay Ministries. Psychoanalysis, Culture \& Society, 20(3), 220-227. doi:10.1057/pcs.2015.25

Courage Philippines. (2012). Powerful Ex-gay Testimony: Danny Wallace. Retrieved from http://couragephilippines.blogspot.com/

D'Augelli, A. R. (1994). Identity development and sexual orientation: Toward a model of lesbian, gay, and bisexual development. In E. J. Trickett, R. J. Watts, \& D. Birman (Eds.), Human diversity: Perspectives on people in context (pp. 312-333). San Francisco: Jossey- Bass.

Haldeman, D. (1994). The Practice and Ethics of Sexual Orientation Conversion Therapy. Journal of Consulting and Clinical Psychology, 62,221-227.

Manalastas, E. J., Ojanen, T. T., Torre, B. A., Ratanashevorn, R., Hong, B. C. C., Kumaresan, V., \& Veeramuthu, V. (2017). Homonegativity in Southeast Asia: Attitudes Toward Lesbians and Gay Men in Indonesia, Malaysia, the Philippines, Singapore, Thailand, and Vietnam. Asia-Pacific Social Sciences Review, 17(1), 25-33.

Robinson, C. and Spivey, S. (2007). The Politics of Masculinity in the Ex-Gay Movement. Gender and Society, 21 (5), 650-675

Shidlo, A. \& Schroeder, M. (2002). Changing Sexual orientation: A Consumers' Report. Professional Psychology: Research and Practice, 33(3), 249-259. doi:10.1037/0735-7028.33.3.249

UNDP., and USAID. (2014). Being LGBT in Asia: The Philippines Country Report. Retrieved from https://www.usaid.gov/sites/default/files/documents/1861/2014\%20UNDPUSAID\%20Philippines\%20LGBT\%20Country\%20Report\%20-\%20FINAL.pdf

Weiss, E., Morehouse, J., Yeager, T., \& Berry, T. (2010). A Qualitative Study of Ex-gay and Ex-Ex-gay Experiences. Journal of Gay \& Lesbian Mental Health, 14(4), 291-319. doi:10.1080/19359705.2010.506412 